\title{
Genomics and Bacterial Metabolism
}

\author{
Diana M. Downs \\ Department of Bacteriology, University of Wisconsin, \\ Madison, 1550 Linden Dr., Madison, WI 53706 USA
}

\begin{abstract}
The field of bacterial metabolism and physiology is arguably the oldest in microbiology. Much of our understanding of biological processes and molecular paradigms has its roots in early studies of prokaryotic physiology. After a period of declining interest in metabolic studies (prompted by the insurgence of molecular techniques), genomic technologies are revitalizing the study of bacterial metabolism and physiology. These new technologies bring a means to approach metabolic questions with a global perspective. When used in combination with classical and molecular techniques, emerging global technologies will make it feasible to understand the complex integration of metabolic processes that result in an efficient physiology. At the same time, without increased computational capabilities, the massive amounts of data generated by these technologies threaten to overwhelm, rather than facilitate, this work. For genomic technologies to reach their potential for increasing our understanding of bacterial metabolism, microbiologists must become more collaborative and multidisciplinary than at any time in our history.
\end{abstract}

\section{Introduction}

At the core of any living cell is metabolism, the sum total of all the biochemical processes contributing to cell function. Coordination of these processes results in the physiology we associate with each organism, from bacteria to humans. The field of bacterial metabolism and physiology is arguably the oldest in microbiology. Through the years investigators have recognized the need to understand the fundamental principles of life processes and realized the advantages of using prokaryotic cells to achieve this. The field of microbial physiology has changed through the years. With the advent of techniques that allowed researchers to focus more on molecular details of gene structure, organization and expression, research and interest in classical metabolism and physiology declined. Knowledge of complete genome sequences and the ability to visualize the transcription of entire genomes have brought a renewed appreciation of the need to understand the physiology and metabolism of a bacterial cell. Thus a new generation of microbial physiologists is emerging; those with genetic, biochemical, molecular, and genomic tools in their hands. Without a

*For correspondence. Email downs@bact.wisc.edu; Tel. 608-265-4630; Fax. 608-262-9865. doubt, the application of this powerful combination of approaches to the study of bacterial metabolism and physiology will result in impressive strides in our understanding of basic metabolic processes and their integration. While newly developed technologies will facilitate progress in understanding metabolism, it is critical to keep in mind that the classical approaches, and rigorous definition of biochemical function must not be lost in the mix.

\section{Genomic Techniques Encourage Global Thinking}

Since the term was coined by Thomas Roderick in 1987, the field of genomics has undergone extensive growth. Initial skepticism from the scientific community about the validity and reproducibility of global techniques (e.g., expression arrays) has largely been replaced by an appreciation for the value of the data that can be generated. This appreciation remains appropriately tempered by a recognition of the limitations of these techniques. Commentaries and critiques continue to force the field to reassess techniques, approaches, conclusions, and goals (Downs and Escalante-Semerena, 2000; Gronow and Brade, 2001; Perego and Hoch, 2001; Zhou and Miller, 2002). The success of this field can be measured by the impact it has had on investigators in all biological disciplines. The flood of press and data generated by global technologies has facilitated, and in fact encouraged, investigators to realize that each subject they study is also a component of a larger complex system. This realization has brought the field of microbial physiology full cycle. Classical microbial physiologists considered the contributions of a whole system, whether it was a cell or a population of cells, when they measured properties of carbon utilization, nitrogen fixation, etc. The advent of molecular biology brought a new opportunity to understand molecular details of components within the cell. The premise that a detailed knowledge of the components would provide an understanding of the whole, encouraged decades of reductionist studies that have produced a solid understanding of a large number of molecular processes. Now, with the advent/implementation of global technologies, the pendulum is swinging back, and research characterized by a global perspective is increasing. In the same way classical physiology was enhanced by molecular techniques, emerging genomic technologies provide another dimension to the study of bacterial metabolism/ physiology. Data from global analyses (expression profiles, protein profiles, etc.) provide a framework to identify correlations and generate hypotheses. The pursuit and rigorous testing of these hypotheses, not the accumulation of data, will characterize the success of metabolic studies in the genomics era.

Technology has advanced to the point that expression profiles, protein profiles, and other global patterns, are routine enough to be used as a "global phenotype". Reports of global analyses (particularly expression arrays) are 
increasing exponentially in the literature. From these data new hypotheses about the role of a sequence, the function of a protein or the extent of a regulon, are being generated. These technologies force a broad perspective that previous researchers did not have, and thus provide an additional context in which metabolic dogmas can be tested. When the data analyses from global technologies generate new hypotheses and force old dogmas to be questioned, it provides a healthy infusion into the field of bacterial metabolism and physiology (Gonzalez et al., 2002; Rhodius et al., 2002; Wassarman et al., 2001).

For all the potential of approaches using global techniques, caution must be taken with their use. A tenet long held by biologists is that genes expressed together are utilized together. While a valid hypothesis, this tenet is not a basis to assign function. The number of expression profiles being reported is becoming overwhelming. Among these are global data obtained from numerous bacteria, different growth conditions, and different genetic backgrounds. They represent regulation of gene expression due to nutrient deprivation, antibiotic treatment, and carefully chosen genetic defects (Karlin et al., 2001; $\mathrm{Ng}$ et al., 2003; Tao et al., 1999; Weber and Jung, 2002; Zheng et al., 2001). Without question these studies have opened new and exciting directions for research in our efforts to understand gene function and the complexities of bacterial metabolism. The sensitivity of these techniques to small differences in expression levels, and the fact that populations are being analyzed, make it critical that investigators are conscious of subtle changes that might occur in growth conditions or sample preparation. Without careful controls, investigators can misinterpret the cause (and thus the relevance) of the variations in expression detected. In addition, a change in transcript level can reflect either direct or indirect effects of the parameter being addressed. Further, the level of transcription does not always correlate with the level of protein, much less functional protein. For this reason, the global analysis of protein (i.e., proteomics) is gaining popularity (Jungblut et al., 2001).

Global analyses of gene expression are being preformed by investigators from a variety of disciplines with a number of goals. While this use reflects the broad value of these technologies, this diversity and rapid growth make it more difficult to enforce standards in the technology. If genomic technologies are to be used efficiently, efforts must be made to ensure the data from these studies are considered in the context of existing metabolic literature. Relevant research results from the past should be identified and addressed in models that are presented based on genomic data. Maintaining this inclusion becomes difficult as researchers from multiple disciplines, that may not be aware of this literature, employ these technologies. Conclusions about metabolism based on genomic technologies that appear to violate a vast literature, need to be recognized and discussed. When considered in isolation, expression array data is of limited use, but in combination with knowledge from decades of metabolic and regulatory studies, it can generate a deeper understanding of bacterial metabolism and physiology. If the extensive literature from previous metabolic studies is not incorporated into the thinking supported by new technologies, investigators will too often end up "rediscovering the wheel".

The amount of literature one must be aware of to ensure identifying all processes that may impinge on a single pathway in the cell is staggering. A concern with global approaches is that so much data can be generated so quickly, it will be nearly impossible for an investigator to identify and incorporate the literature that he/she should be aware of in interpreting these data. Collaboration and extensive communication between researchers versed in genomic approaches and those with a knowledge of classical physiology and metabolism, in addition to advances in data storage/analysis, will help address this concern.

\section{Model Organisms-Extending the Paradigms}

Results from genome sequencing efforts have emphasized that metabolic processes are conserved in diverse living organisms. These results have led to approaches to reconstruct metabolism in diverse organisms in silico (Castresana, 2001; Mittenhuber, 2001; Schilling et al., 2002). Perhaps more importantly, this realization has reinvigorated metabolic research in prokaryotes and validated the study of model microorganisms as a means to define metabolic paradigms. In the case of metabolic analyses, one requirement of a model organism is that in vivo analyses are possible. Numerous reports appear every month, of work in model organisms (e.g., E. coli, S. enterica, B.subtillis) that has been prompted, facilitated, and/or justified by comparative genomic analyses. Frequently one reads about a locus and/or phenomenon identified in a non-model organism and investigators are quickly drawn to the system in E. coli (or other model organism) due to technical ease, and the vast metabolic knowledge base in this bacterium. An example of this scenario is the study of Fe-S cluster biogenesis, a field that has undergone explosive growth in the last ten years. Work by Dean and others on nitrogenase in $A$. vinelandii identified gene products (NifSUA) required for the formation of metal clusters in this complex enzyme system (Jacobson et al., 1989; Zheng et al., 1993). These results were followed by the identification of a similar set of genes (isc) elsewhere in the chromosome of $A$. vinelandii (Zheng et al., 1998), and the subsequent demonstration that these genes were conserved from bacteria to humans, and had a critical role in the biogenesis of Fe-S clusters in vivo (Campos-Garcia and Soberon-Chavez, 2000; Hoff et al., 2000; Lill and Kispal, 2000; Mansy et al., 2002; Schwartz et al., 2000; Seidler et al., 2001; Skovran and Downs, 2000; Tachezy et al., 2001; Takahashi and Nakamura, 1999; Voisine et al., 2001). While the biochemistry of the gene products has been pursued in a number of organisms, research on the genetic locus as well as its regulation, and physiological role of the gene products has been most rapid in model organisms (Hoff et al., 2000; Kambampati and Lauhon, 2000; Kambampati and Lauhon, 1999; Ollagnier-deChoudens et al., 2001; Schwartz et al., 2001; Smith et al., 2001; Tokumoto and Takahashi, 2001; Urbina et al., 2001). The emerging characterization of the sufgenes (recognized 
now to be at least partially redundant with the Isc system) provides more evidence of the productivity that can be obtained by studying the relevant problem in a model organism, and combining these results with the input of data from work in other systems (Patzer and Hantke, 1999; Rangachari et al., 2002). The rapid growth in this, and other, fields of metabolism can be largely attributed the presence of comparative genomic technologies.

A slightly different example involves identification of a locus in the model organism, that has a homolog identified or studied for its role in a metabolic process(es) in a distinct organism. If, as is often the case in genetically tractable organisms, the lesion was identified by a phenotypic screen, the studies of homologs can provide a new perspective for the functional characterization that follows. The recent work on competence gene homologs in E.coli by Finkel et al. is a good illustration of this scenario. In this case, use of novel phenotypic analyses (i.e., competitiveness in long-term stationary phase), led to the identification of genes required for the ability of $E$. coli to use DNA as a nutrient (Finkel and Kolter, 2001). Although not surprising in retrospect, the genes involved were homologs of genes in Haemophilus influenzae and Neisseria gonorrhoeae that had been ascribed a role in natural competence (Dougherty and Smith, 1999; Smith et al., 1995). This finding facilitates progress in the understanding of two distinct, but similar metabolic processes. In the absence of comparative genomic technologies, each of the research groups would have a more difficult time identifying a function and physiological role of the gene(s) involved in their respective processes. This example also highlights the benefit that would be derived from knowing the physical identity of genetic loci that have been described in the literature. Such a correlation would allow researchers to take advantage of the physiology and phenotypes that have been described for mutants in multiple systems throughout the years.

While the above examples are directly impacted by the plethora of genome sequences and comparative genomic technologies, arguably the most important work in model organisms is the continuation of the efforts aimed at understanding basic metabolism that have been preformed for decades. This kind of methodical metabolic and molecular work will continue to define metabolic processes and paradigms, thus facilitating work in other systems. One should remember that a major factor in the speed at which genomic analyses of organisms progresses is the base of metabolic knowledge, and molecularly defined paradigms that have arisen as a the result of decades of rigorous biochemistry, genetics, and molecular biology in the model organisms. Model organisms provide the logical forum to continue the molecular characterization of cellular processes, and uncover new metabolic paradigms. Without this work, the risk exists that analysis of sequence data will degenerate into no more than a means to catalog genes and proteins. A mechanism must remain in place to uncover new areas of research and functional paradigms. Genomic and sequencing technologies have not provided a magic bullet for understanding metabolism, they are simply one more tool in the arsenal available to the modern microbial physiologist. The need for solid basic metabolic research in model organisms is unlikely to diminish in the foreseeable future.

\section{Model Organisms Facilitate Genomic Analysis of Diverse Organisms}

The use of model organisms goes beyond analysis of their own metabolism. Model organisms are designated as such because they offer technical ease, a property that can be useful in probing the metabolism of other organisms. The annotated genomes of model organisms provide functional information that is more difficult to access in less tractable systems. For instance, complementation of a mutant phenotype in genetically less tractable organisms by an $E$. coli clone of known function can provide insight about the function disrupted in the parent strain. Conversely, genetically defined organisms can be used to identify functional homologs from diverse organisms. Plasmid libraries of DNA from an organism of interest can be generated in a vector that can replicate in E.coli. When these plasmids are introduced to the appropriate mutant strain of E. coli, the plasmid(s) that complement the defect are candidates for carrying a functional homolog of the protein missing in the E. coli mutant (Bull et al., 1994; Pascopella et al., 1994). Use of heterologous systems (often but not always $E$. coli) has become prevalent in identifying genetic or biochemical functions from less tractable systems. The technologies available, in combination with comparative genomic capabilities have almost made $E$. coli a required lab reagent.

Metabolic properties of diverse organisms can be identified and studied by introducing the genetic material required for the relevant metabolism into model host organisms (Handelsman et al., 1998; Rondon et al., 1999; Weinstock et al., 2000). This approach has been championed in the emerging fields of metagenomics (Rondon et al., 2000) and metabolic engineering (Cameron and Chaplen, 1997). In the former, metabolic capabilities (e.g., antibiotic production) can be identified even in the absence of a culturable parent organism. Appropriate host strains are identified based on the metabolic process of interest and other properties. Using this principle, metabolic capabilities can be "mined" from any environment by obtaining, and cloning, heterogenous DNA preparations. Following introduction of the resulting clones into the appropriate organism, a metabolic capability of interest can be identified as a "gained property" of the host organism. In the second, slightly different situation, organisms with properties of interest are used as a source of donor DNA. In this case, the desired metabolic property is often an ability to biosynthesize an antibiotic, or a given compound whose biosynthetic pathway is the target of engineering focus (Trauger and Walsh, 2000). The primary assumptions of these approaches are that, i) the host organism will provide "supporting metabolism" such that what is identified is the genetic information uniquely needed for the respective metabolic property, and ii) the genetic material for this process is located in a single region of the donor chromosome, such that is will be contained on a contiguous piece of DNA. These assumptions are more or less valid 
depending on the situation, but the ease at which these kinds of approaches can now be applied, have attracted the attention of investigators in academia and industry. After the genetic material is identified from in vivo (or in situ) sources, it is useful in metabolic engineering efforts, where DNA encoding desired functions can be manipulated and/ or mutagenized, to design and modify pathways for commercial gain (Aldor and Keasling, 2001; Aldor et al., 2002; McDaniel et al., 1999; Pfeifer et al., 2001; Pfeifer and Khosla, 2001; Stachelhaus et al., 1995).

In the above cases illustrating the potential for studies with heterologous metabolisms, the limitations of the system should be kept in mind. While these approaches offer a powerful starting point, the integrated metabolism of each organism is the result of years of selective pressures and the subtleties of regulation and efficiency are unlikely to be mimicked in heterologous systems. While manipulating these genomes and organisms to reach a goal or target a component, the benefit of understanding homogeneous systems should be kept in mind and pursued at a later point.

\section{Functional Genomics - Or Classical Genetics?}

At some level the goal of all microbial physiologists is to understand the function(s) of each protein and how they work together to result in the efficient physiology we associate with a living cell. The work of most investigators falls somewhere along the continuum of identifying a gene, to understanding its role and interactions in vivo. For a number of reasons, few labs strive to span the entire continuum. The more common scenario is when a genomic investigation identifies gene(s) that are connected (i.e., by regulation, location, homology, etc.,) to the area of research focus in a laboratory. In these situations, a putative function for the gene product often exists based on information that led to an interest in this gene. The function of the relevant gene is then pursued in the context of other research in the laboratory. Another powerful means to identify functionally connected components in vivo is by using genetic suppressor analysis. This approach will identify genes that are involved in a process of interest, however indirectly (Downs and Escalante-Semerena, 2000; EnosBerlage and Downs, 1997; Enos-Berlage et al., 1998; Gralnick and Downs, 2001; Petersen et al., 1996). The difficulty in this approach is that genes that are identified by these mutant analyses often have no obvious connection to the process of interest. Thus the investigator may struggle to define the function of the relevant gene product and the explanation for its interaction with the initial process. So, while this approach has significant potential to provide a functional context for unknown genes in vivo, few investigators take advantage of it.

Efforts aimed at identifying the function of proteins on a global scale fall under the poorly defined rubric of "functional genomics". Often these approaches depend on a transcriptome, proteome, metabolome or the result of characterization by some other "omic" technique (Eymann et al., 2002; Tao et al., 1999; Tumbula and Whitman; Wen and Burne, 2002). Many times these efforts simply result in a catalog of genes with respect to a given condition or genetic background. While these analyses provide valuable data, they are not a demonstration of function. One must realize that cellular function implies a known role in vivo. Understanding the function of a protein in vivo requires that two things be true. First, there must be a biochemical function for the protein that is demonstrable in vitro. Second, lack of this biochemical function must explain the phenotype that results in a cell lacking the relevant protein. Hence neither result alone, and certainly not a solely global analysis, will allow definitive annotation of a gene. A common "functional genomic" strategy being pursued in a number of organisms is to knock out all genes in turn, and analyze the resulting phenotype. While this sounds promising at first, the value of this approach is limited. Consider that in some organisms, notably E. coli/S. enterica, classical genetic approaches, scoring a variety of phenotypes, have been performed for more that 50 years. Without creatively screening phenotypes, how likely is this strategy to uncover genes that have not been identified? In the best case scenario, this approach may identify a few additional genes whose absence results in a clear growth phenotype. An immediate benefit could be derived from these approaches, if the data were interpreted in the context of past literature to assign a physical location to genetically defined loci in the literature (Dougherty and Downs, 2003; Frodyma and Downs, 1998; Roberts and Reeve, 1970; Sanderson and Roth, 1988). After decades of metabolic genetics and biochemistry in a number of organisms, our understanding of basic metabolism is good. Pushing the understanding of metabolism/physiology to the next level will require that creative approaches be used to address phenotypes caused by lack of additional cellular components. It is reasonable that many of the ORFs that remain completely uncharacterized are not required for a process to function, but rather for its optimization. Other genetic approaches must be considered to uncover the subtle and/or conditional defects associated with loss of these accessory or redundant proteins. Strategies that have been successful in identifying proteins with this type function protein include generating synthetic lethal mutants (or synthetic auxotrophs), scoring reduced not eliminated growth, and multi-copy suppression analyses (Gralnick and Downs, 2001; Petersen and Downs, 1996; Petersen et al., 1996; Petersen and Downs, 1997; Trzebiatowski et al., 1994). Other creative approaches wait to be pioneered.

Even at their best, the scenarios described above will identify a condition where the relevant gene product is needed, a far cry from knowing the in vivo biochemical function. The number of proteins whose only homologs are other undefined proteins with a similar motif, suggests we do not have an understanding of all functional classes of proteins. It is possible, and even likely, that these protein families define new functional and biochemical paradigms that have not been characterized. The question becomes how to go past cataloging by sequence similarity and expression studies to identify the biochemical function? This question is at the crux of an ability to extend our understanding of metabolism, and there is no easy answer. Nor is there a computer program with the power to predict function from unique primary sequence. It has been suggested that by determining the crystal structure of these 
uncharacterized proteins, a putative function will be clear. While this structural genomic approach is being pursued in a number of research groups, it is unclear that it has been successful in identifying a function of a completely novel protein (Eisenstein et al., 2000; Volz, 1999; Xu et al., 1999; Zarembinski et al., 1998). It is more likely that work toward functional elucidation will proceed by meticulous "discovery" science that is facilitated by metabolic genetics and biochemistry. Progress in this work cannot be outlined, nor forced, because the outcome is not predictable. These studies must be pursued with a creative mind and the conviction that new paradigms are yet to be discovered. Investigators successful in this research will use molecular, biochemical, genetic and genomic technologies, and follow their scientific intuition. This strategy has resulted in landmark discoveries in the past, and genomic technology has yet to eliminate the need for this kind of unbiased discovery based research.

\section{Data Management and Dissemination}

With genomic technologies have come unprecedented volumes of data that must be cataloged, mined and analyzed. This is a major challenge for computational scientists, and significant efforts are being made to ensure data management keeps pace with progress of genomic technologies (Covert et al., 2001; Edwards et al., 2002; ;Edwards et al., 2001; Edwards et al., 2002; Krauthammer et al., 2002; Mendes, 2002; Palsson, 2002; Papin et al., 2002; Wagner, 2001). While the challenges of designing software to handle, screen and analyze these data are recognized, there are additional data management and dissemination needs required for research in bacterial metabolism to progress efficiently. These challenges include the need to: i) make data broadly available, ii) rigorously and rapidly update genomic annotations, and iii) define common nomenclature rules. The field of metabolism and physiology is characterized by its integrative nature. Progress in this field, more than most, is dependent on the access to knowledge of numerous pathways/processes. Because information that must be considered in metabolic studies is becoming so diverse and widespread, it is often not identified by current researchers and this slows progress and increases redundancy of effort. Much of the potential for efficient progress promised by global techniques will be lost if the scientific community cannot simply determine what data are there to support one or another conclusion.

Correct and current annotation of sequenced genomes is critical for metabolic studies. As mentioned above, significant work on unknown genes, and new genes in diverse organisms is dictated by sequence similarity to annotated genes in model organisms. If investigators are allowed to describe the function of a gene based solely on similarity to an annotated gene in a different organism, and the respective annotation is incorrect or not definitive, the literature can become compromised in a way that is hard to reverse. It is imperative that biologists be involved in updating the annotations and that the standard for annotation be clearly stated in each case, such that appropriate, defensible, conclusions can be made when sequence similarity is detected.

Post-genomic nomenclature is also a concern for the efficiency of metabolic studies (Fields and Johnston, 2002). Genes have traditionally been named based on phenotypic analysis and this has led to problems when the biochemical function of the gene product is determined (Frodyma and Downs, 1998; Skovran and Downs, 2003; Trzebiatowski et al., 1994). A better solution is the current trend to name genes based on chromosomal location (i.e., YXX, or STM) until a biochemical function can be attributed to the gene product (K. Sanderson and M. Berlyn, personal communication). This is not yet a perfect solution, since, in E. coli, both a "b" designation, and the "yxx" designation exist and are used. Unfortunately, the literature has been permeated by cases where multiple names for the same gene are used. Not only is this is a problem that is tedious and time consuming to fix, it is unclear whose domain such an effort should fall in. An extension of this issue is the realization that a large amount of useful phenotypic information is present in the literature from the time when loci were genetically, but not physically defined. If a a genetic/physical correlation of these genes were generated, it would allow data from the past to be better incorporated in the context of current work, which is preformed with the mindset of physical location. Unfortunately, in both of the above cases, work to clarify the literature, and eliminate redundancies is unlikely to be preformed on more than a case by case basis unless a major emphasis is put on solving these data management challenges.

In addition to the rather mundane cases described above, there is a growing need for new computational technology to integrate information present in the literature. For metabolic research to move forward productively researchers must be able to consider their results in the context of what is known. We are now in an exciting time where data integration is possible and global thinking is encouraged. Some researchers can be well versed in the connections that exist in a small area of metabolism, but as the understanding of metabolic connections and integration expands, it becomes less feasible for this information to be stored by single investigators.

From the perspective of bacterial metabolism, the challenge facing the computational scientists is to design software that can, i) integrate the information in the literature on individual pathways and processes to present an accessible picture of the metabolic connections that exist in vivo, and ii) scan literature for words or phrases that may be buried within a manuscript of a different focus. In the former case, storage of known connections in a form that can be accessed, modeled, and expanded is needed. Some of this work is beginning, and several databases built with this goal in mind exist (Goesmann et al., 2002; Karp, 2001; Karp et al., 2002; Karp et al., 2002). As our progress in understanding metabolic integration continues, there should be some mechanism to incorporate these basic research results into the metabolic databases. Display of this information in a useful way will require some creativity. Both direct biochemical connections, and more indirect connections, which can also affect function of a pathway/process, need to be presented. Importantly, these databases need a clear description of which connections/ 
activities are documented by experimental data and which are simply hypothesized.

The second case reflects a need for investigators to find references to a particular metabolic process from the literature when the relevant statement may be a small piece of a manuscript. Classical approaches to metabolic characterization often result in valuable observations, which appear peripheral to the original focus of the project. The significance of these peripheral observations may not be apparent to the authors of the original study. Yet, to investigators focusing on a different area of metabolism, these observations may provide critical insight. In such a scenario, the "side" observation might never be accessed by the relevant researchers, since as a minor statement in the manuscript, it would be invisible to standard literature searches. An ability to search the literature for words and phrases that indicate a metabolic connection would facilitate the integrative thinking that investigators in metabolic studies need. Progress in metabolic studies depends on astute researchers recognizing phenotypes and observations that suggest a key connection or explain a metabolic behavior. The difficulty in the field has been communicating these observations in a way that the relevant person(s) has access to it in their thinking. This area cries out for collaboration and communication between experts in a number of disciplines, and identifies an area that could have an enormous impact on the progress of our understanding of bacterial metabolism. When this concept becomes a reality, perhaps the scientific community as a whole will be more receptive to the value of describing phenomena for which a biochemical explanation is not yet readily available.

\section{Conclusions}

These are exciting times for the field of bacterial metabolism and physiology. It has long been recognized that the cell was comprised of many integrated metabolic pathways and processes. As our knowledge of individual components has increased, we have reached the point where it is no longer enough to consider a single pathway (or process) without regard its integration with the other cellular components. As global technologies and data management strategies continue to be developed, the capacity to present and catalog the integration of multiple pathways and processes will reach a level not possible for the human brain to retain. These capabilities will push our understanding of bacterial metabolism to a higher level of complexity.

Ironically, what seems to draw researchers to genomic analyses, i.e., the volume of data reflecting activity in the whole cell, is similar to the characteristics that often drive investigators from the more classical approaches to physiology and metabolism. The methodical "discovery" science of classical metabolic genetics and biochemistry is often characterized by slow paced, weaving progress with numerous wrong turns, required to generate and discard models that can explain complex phenotypes in the context of the cellular biochemistry. The field of bacterial metabolism is characterized by a self-imposed mandate to consider metabolic processes in the context of cellular physiology, rather than in isolation. The difficulty these researchers face is the volume of data, and knowledge of diverse metabolic pathways they must be able to draw from to generate an inclusive model. Computational science has the potential to ease this difficulty in the future and facilitate the integration of data generated from multidisciplinary approaches to metabolism.

Genomic technologies and data analysis techniques are powerful tools to probe bacterial metabolism but they have yet to replace the curiosity and creativity of the human mind in making progress. These technologies have allowed the rapid cataloging of sequence similarities and differences, common regulatory themes and protein stability. The challenge in the field of physiology and metabolism in the future will be to take advantage of these technologies without losing an open mind and the drive to pursue the exceptions, or the pieces that do not fit existing paradigms. Thus, in addition to genomic technologies, creativity and persistence will be required if we are to take our knowledge of cellular processes and understanding of metabolic integration to the next level by continuing to define biological paradigms.

\section{Acknowledgements}

D.M.D. is supported by National Institutes of Health grant GM47296, National Sciences Foundation grant MCB9723830, and a $21^{\text {st }}$ Century Scientist Award from the J.S. McDonnell Foundation.

\section{References}

Aldor, I., and Keasling, J.D. 2001. Metabolic engineering of poly(3-hydroxybutyrate-co-3-hydroxyvalerate) composition in recombinant Salmonella enterica serovar typhimurium. Biotechnol Bioeng 76: 108-114.

Aldor, I.S., Kim, S.W., Prather, K.L., and Keasling, J.D. 2002. Metabolic engineering of a novel propionateindependent pathway for the production of poly(3Hydroxybutyrate-co-3-hydroxyvalerate) in recombinant Salmonella enterica serovar Typhimurium. Appl. Environ. Microbiol. 68: 3848-3854.

Bull, C.T., Ishimaru, C.A., and Loper, J.E. 1994. Two Genomic Regions Involved in Catechol Siderophore Production by Erwinia carotovora. Appl. Environ. Microbiol. 60: 662-669.

Cameron, D.C., and Chaplen, F.W. 1997. Developments in metabolic engineering. Curr. Opin. Biotechnol. 8: 175180.

Campos-Garcia, J., Ordóñez, L.G., and Soberon-Chavez, G. 2000. The Pseudomonas aeruginosa hscA gene encodes Hsc66, a DnaK homologue. Microbiol. 146: 1429-1435.

Castresana, J. 2001. Comparative genomics and bioenergetics. Biochim. Biophys. Acta. 1506: 147-162.

Covert, M.W., Schilling, C.H., Famili, I., Edwards, J.S., Goryanin, II., Selkov, E., and Palsson, B.O. 2001. Metabolic modeling of microbial strains in silico. Trends Biochem. Sci. 26: 179-186.

Dougherty, B.A., and Smith, H.O. 1999. Identification of Haemophilus influenzae Rd transformation genes using cassette mutagenesis. Microbiol. 145: 401-409. 
Dougherty, M., and Downs, D.M. 2003. The stm4066gene product of Salmonella enterica serovar Typhimurium has aminoimidazole riboside (AIRs) kinase activity, and allows AIRs to satisfy the thiamin requirement of pur mutant strains. J. Bacteriol. 185: 332-339.

Downs, D.M., and Escalante-Semerena, J.C. 2000. Impact of genomics and genetics on the elucidation of bacterial metabolism. Methods. 20: 47-54.

Edwards, J.S., Covert, M., and Palsson, B. 2002. Metabolic modelling of microbes: the flux-balance approach. Environ. Microbiol. 4: 133-140.

Edwards, J.S., Ibarra, R. U., and Palsson, B.O. 2001. In silico predictions of Escherichia colimetabolic capabilities are consistent with experimental data. Nat. Biotechnol. 19: 125-130.

Edwards, J.S., Ramakrishna, R., and Palsson, B.O. 2002. Characterizing the metabolic phenotype: a phenotype phase plane analysis. Biotechnol. Bioeng. 77: 27-36.

Eisenstein, E., Gilliland, G.L., Herzberg, O., Moult, J., Orban, J., Poljak, R.J., Banerjei, L., Richardson, D., and Howard, A.J. 2000. Biological function made crystal clearannotation of hypothetical proteins via structural genomics. Curr. Opin. Biotechnol. 11: 25-30.

Enos-Berlage, J.L., and Downs, D.M. 1997. Mutations in sdh (succinate dehydrogenase genes) alter the thiamine requirement of Salmonella typhimurium. J. Bacteriol. 179: 3989-3996.

Enos-Berlage, J.L., Langendorf, M.J., and Downs, D.M. 1998. Complex metabolic phenotypes caused by a mutation in $y j g F$, encoding a member of the highly conserved YER057c/YjgF family of proteins. J. Bacteriol. 180: 6519-6528.

Eymann, C., Homuth, G., Scharf, C., and Hecker, M. 2002. Bacillus subtilis functional genomics: global characterization of the stringent response by proteome and transcriptome analysis. J. Bacteriol. 184: 2500-2520.

Fields, S., and Johnston, M. 2002. Genomics. A crisis in postgenomic nomenclature. Science. 296: 671-672.

Finkel, S.E., and Kolter, R. 2001. DNA as a nutrient: novel role for bacterial competence gene homologs. J. Bacteriol. 183: 6288-6293.

Frodyma, M., and Downs, D.M. 1998. The panE gene, encoding ketopantoate reducatse, maps at 10 minutes and is allelic to $a p b A$ in Salmonella typhimurium. J. Bacteriol. 180: 4757-4759.

Goesmann, A., Haubrock, M., Meyer, F., Kalinowski, J., and Giegerich, R. 2002. PathFinder: reconstruction and dynamic visualization of metabolic pathways. Bioinformatics. 18: 124-129.

Gonzalez, R., Tao, H., Shanmugam, K.T., York, S.W., and Ingram, L.O. 2002. Global gene expression differences associated with changes in glycolytic flux and growth rate in Escherichia coliduring the fermentation of glucose and xylose. Biotechnol. Prog. 18: 6-20.

Gralnick, J., and Downs, D. 2001. Protection from superoxide damage associated with an increased level of the YggX protein in Salmonella enterica. Proc. Natl. Acad. Sci. USA. 98: 8030-5.

Gronow, S., and Brade, H. 2001. Lipopolysaccharide biosynthesis: which steps do bacteria need to survive? J. Endotoxin. Res. 7: 3-23.
Handelsman, J., Rondon, M.R., Brady, S.F., Clardy, J., and Goodman, R.M. 1998. Molecular biological access to the chemistry of unknown soil microbes: a new frontier for natural products. Chem. Biol. 5: R245-249.

Hoff, K.G., Silberg, J.J., and Vickery, L.E. 2000. Interaction of the iron-sulfur cluster assembly protein IscU with the Hsc66/Hsc20 molecular chaperone system of Escherichia coli. Proc. Natl. Acad. Sci. USA. 97: 7790-7795.

Jacobson, M.R., Cash, V.L., Weiss, M.C., Laird, N.F., Newton, W.E., and Dean, D.R. 1989. Biochemical and genetic analysis of the nifUSVWZM cluster from Azotobacter vinelandii. Mol. Gen. Genet. 219: 49-57.

Jungblut, P.R., Muller, E.C., Mattow, J., and Kaufmann, S.H. 2001. Proteomics reveals open reading frames in Mycobacterium tuberculosis H37Rv not predicted by genomics. Infect. Immun. 69: 5905-5907.

Kambampati, R., and Lauhon, C.T. 2000. Evidence for the transfer of sulfane sulfur from IscS to Thil during the in vitro biosynthesis of 4-thiouridine in Escherichia colitRNA. J. Biol. Chem. 275: 10727-10730.

Kambampati, R., and Lauhon, C.T. 1999. IscS is a sulfurtransferase for the in vitro biosynthesis of 4thiouridine in Escherichia colitRNA. Biochem. 38: 1656116568.

Karlin, S., Mrazek, J., Campbell, A., and Kaiser, D. 2001. Characterizations of highly expressed genes of four fastgrowing bacteria. J. Bacteriol. 183: 5025-5040.

Karp, P.D. 2001. Pathway databases: a case study in computational symbolic theories. Science. 293: 20402044.

Karp, P.D., Riley, M., Paley, S.M., and Pellegrini-Toole, A. 2002. The MetaCyc Database. Nucleic Acids Res. 30: 59-61.

Karp, P.D., Riley, M., Saier, M., Paulsen, I.T., Collado-Vides, J., Paley, S.M., Pellegrini-Toole, A., Bonavides, C., and Gama-Castro, S. 2002. The EcoCyc database. Nucleic Acids Res. 30: 56-58.

Krauthammer, M., Kra, P., lossifov, I., Gomez, S.M., Hripcsak, G., Hatzivassiloglou, V., Friedman, C., and Rzhetsky, A. 2002. Of truth and pathways: chasing bits of information through myriads of articles. Bioinformatics. 18: S249-S257.

Lill, R., and Kispal, G. 2000. Maturation of cellular Fe-S proteins: an essential function of mitochondria. Trends Biochem. Sci. 25: 352-356.

Mansy, S.S., Wu, G., Surerus, K.K., and Cowan, J.A. 2002. Iron-sulfur cluster biosynthesis: Thermatoga maritima IscU is a structured iron-sulfur cluster assembly protein. J. Biol. Chem. 4: 4.

McDaniel, R., Thamchaipenet, A., Gustafsson, C., Fu, H., Betlach, M., and Ashley, G. 1999. Multiple genetic modifications of the erythromycin polyketide synthase to produce a library of novel "unnatural" natural products. Proc. Natl. Acad. Sci. USA. 96: 1846-18451.

Mendes, P. 2002. Emerging bioinformatics for the metabolome. Brief Bioinformatics. 3: 134-145.

Mittenhuber, G. 2001. Phylogenetic analyses and comparative genomics of vitamin B6 (pyridoxine) and pyridoxal phosphate biosynthesis pathways. J. Mol. Microbiol. Biotechnol. 3: 1-20.

Ng, W.L., Kazierczak, K.M., Robertson, G.T., Gilmour, R., 
and Winkler, M.E. 2003. Transcription Regulation and Signature Patterns Revealed by Microarray Analyses of Streptococcus pneumoniae R6 challenged with SubLethal Concentrations of Translation Inhibitors. J. Bacteriol. In press.

Ollagnier-de-Choudens, S., Mattioli, T., Takahashi, Y., and Fontecave, M. 2001. Iron-sulfur cluster assembly: characterization of IscA and evidence for a specific and functional complex with ferredoxin. J. Biol. Chem. 276: 22604-22607.

Palsson, B. 2002. In silico biology through "omics". Nat. Biotechnol. 20: 649-650.

Papin, J.A., Price, N.D., Edwards, J.S., and Palsson, B.B. 2002. The genome-scale metabolic extreme pathway structure in Haemophilus influenzae shows significant network redundancy. J. Theor. Biol. 215: 67-82.

Pascopella, L., Collins, F.M., Martin, J.M., Lee, M.H., Hatfull, G.F., Stover, C.K., Bloom, B.R., and Jacobs, W.R. Jr. 1994. Use of in vivo complementation in Mycobacterium tuberculosis to identify a genomic fragment associated with virulence. Infect. Immun. 62: 1313-1319.

Patzer, S.I., and Hantke, K. 1999. SufS is a NifS-like protein, and SufD is necessary for stability of the [2Fe-2S] FhuF protein in Escherichia coli. J. Bacteriol. 181: 3307-3309.

Perego, M., and Hoch, J.A. 2001. Functional Genomics of Gram-Positive Microorganisms: review of the meeJ. A.ting, San Diego, California, 24 to 28 June 2001. J. Bacteriol. 183: 6973-6978.

Petersen, L., and Downs, D.M. 1996. Mutations in apbC ( $m r p)$ prevent function of the alternative pyrimidine biosynthetic pathway in Salmonella typhimurium. J. Bacteriol. 178: 5676-5682.

Petersen, L., Enos-Berlage, J., and Downs, D.M. 1996. Genetic analysis of metabolic crosstalk and its impact on thiamine synthesis in Salmonella typhimurium. Genetics. 143: 37-44.

Petersen, L.A., and Downs, D.M. 1997. Identification and characterization of an operon in Salmonella typhimurium D. M. involved in thiamine biosynthesis. J. Bacteriol. 179: 4894-4900.

Pfeifer, B.A., Admiraal, S.J., Gramajo, H., Cane, D.E., and Khosla, C. 2001. Biosynthesis of complex polyketides in a metabolically engineered strain of $E$. coli. Science. 291: 1790-1792.

Pfeifer, B.A., and Khosla, C. 2001. Biosynthesis of Polyketides in Heterologous Hosts. Microbiol. Mol. Biol. Rev. 65: 106-118.

Rangachari, K., Davis, C.T., Eccleston, J.F., Hirst, E.M., Saldanha, J.W., Strath, M., and Wilson, R.J. 2002. SufC hydrolyzes ATP and interacts with SufB from Thermotoga maritima. FEBS Lett. 514: 225-228.

Rhodius, V., Van Dyk, T.K., Gross, C., and LaRossa, R.A. 2002. Impact of genomic technologies on studies of bacterial gene expression. Ann. Rev. Microbiol. 56: 599624.

Roberts, L.M., and Reeve, E.C.R. 1970. Two mutations giving low-level streptomycin resistance in Escherichia coli K12. Genet. Res. 16: 359-365.

Rondon, M.R., August, P.R., Bettermann, A.D., Brady, S.F., Grossman, T.H., Liles, M. R., Loiacono, K.A., Lynch, B.A., MacNeil, I.A., Minor, C., Tiong, C.L., Gilman, M., Osburne,
M.S., Clardy, J., Handelsman, J., and Goodman, R. M. 2000. Cloning the soil metagenome: a strategy for accessing the genetic and functional diversity of uncultured microorganisms. Appl. Environ. Microbiol. 66: 2541-2547.

Rondon, M. R., Raffel, S.J., Goodman, R.M., and Handelsman, J. 1999. Toward functional genomics in bacteria: analysis of gene expression in Escherichia coli from a bacterial artificial chromosome library of Bacillus cereus. Proc. Natl. Acad. Sci. USA. 96: 6451-6455.

Sanderson, K.E., and Roth, J.R. 1988. Linkage map of Salmonella typhimurium, Edition VII. Microbiol. Rev. 52: 485-532.

Schilling, C.H., Covert, M.W., Famili, I., Church, G.M., Edwards, J.S., and Palsson, B.O. 2002. Genome-scale metabolic model of Helicobacter pylori26695. J. Bacteriol. 184: 4582-4593.

Schwartz, C.J., Djaman, O., Imlay, J.A., and Kiley, P.J. 2000. The cysteine desulfurase, IscS, has a major role in in vivo Fe-S cluster formation in Escherichia coli. Proc. Natl. Acad. Sci. USA. 97: 9009-9014.

Schwartz, C.J., Giel, J.L., Patschkowski, T., Luther, C., Ruzicka, F.J., Beinert, H., and Kiley, P.J. 2001. IscR, an Fe-S cluster-containing transcription factor, represses expression of Escherichia coli genes encoding Fe-S cluster assembly proteins. Proc. Natl. Acad. Sci. USA. 98: 14895-14900.

Seidler, A., Jaschkowitz, K., and Wollenberg, M. 2001. Incorporation of iron-sulphur clusters in membrane-bound proteins. Biochem. Soc. Trans. 29: 418-421.

Skovran, E., and Downs, D.M. 2003. Lack of ApbC or ApbE proteins results in a defect in Fe-S cluster Metabolism in Salmonella enterica serovar Typhimurium. J. Bacteriol.185: 98-106.

Skovran, E., and Downs, D.M. 2000. Metabolic defects caused by mutations in the isc gene cluster in Salmonella enterica serovar Typhimurium: implications for thiamine synthesis. J. Bacteriol. 182: 3896-3903.

Smith, A.D., Agar, J.N., Johnson, K.A., Frazzon, J., Amster, I.J., Dean, D.R., and Johnson, M.K. 2001. Sulfur transfer from IscS to IscU: the first step in iron-sulfur cluster biosynthesis. J. Am. Chem. Soc. 123: 11103-11104.

Smith, H.O., Tomb, J.F., Dougherty, B.A., Fleischmann, R.D., and Venter, J.C. 1995. Frequency and distribution of DNA uptake signal sequences in the Haemophilus influenzae Rd genome. Science. 269: 538-540.

Stachelhaus, T., Schneider, A., and Marahiel, M.A. 1995. Rational design of peptide antibiotics by targeted replacement of bacterial and fungal domains. Science. 269: 69-72.

Tachezy, J., Sanchez, L.B., and Muller, M. 2001. Mitochondrial type iron-sulfur cluster assembly in the amitochondriate eukaryotes Trichomonas vaginalis and Giardia intestinalis, as indicated by the phylogeny of IscS. Mol. Biol. Evol. 18: 1919-28.

Takahashi, Y., and Nakamura, M. 1999. Functional assignment of the ORF2-iscS-iscU-iscA-hscB-hscA-fdxORF3 gene cluster involved in the assembly of Fe-S clusters in Escherichia coli. J. Biochem. (Tokyo) 126: 91726.

Tao, H., Bausch, C., Richmond, C., Blattner, F.R., and 
Conway, T. 1999. Functional genomics: expression analysis of Escherichia coligrowing on minimal and rich media. J. Bacteriol. 181: 6425-6440.

Tokumoto, U., and Takahashi, Y. 2001. Genetic analysis of the isc operon in Escherichia coli involved in the biogenesis of cellular iron-sulfur proteins. J. Biochem. (Tokyo) 130: 63-71.

Trauger, J.W., and Walsh, C.T. 2000. Heterologous expression in Escherichia coli of the first module of the nonribosomal peptide synthetase for chloroeremomycin, a vancomycin-type glycopeptide antibiotic. Proc. Natl. Acad. Sci. USA. 97: 3112-3117.

Trzebiatowski, J.R., O'Toole, G.A., and EscalanteSemerena, J.C. 1994. The cobT gene of Salmonella typhimurium encodes the NaMN: 5, 6dimethylbenzimidazole phosphoribosyltransferase responsible for the synthesis of N1-(5-phospho-alpha-Dribosyl)-5, 6-dimethylbenzimidazole, an intermediate in the synthesis of the nucleotide loop of cobalamin. J. Bacteriol. 176: 3568-3575.

Tumbula, D.L., and Whitman, W.B. 1999. Genetics of Methanococcus: possibilities for functional genomics in Archaea. Mol. Microbiol. 33: 1-7.

Urbina, H.D., Silberg, J.J., Hoff, K.G., and Vickery, L.E. 2001. Transfer of sulfur from IscS to IscU during Fe/S cluster assembly. J. Biol. Chem. 276: 44521-44526.

Voisine, C., Cheng, Y.C., Ohlson, M., Schilke, B., Hoff, K., Beinert, H., Marszalek, J., and Craig, E.A. 2001. Jac1, a mitochondrial $\mathrm{J}$-type chaperone, is involved in the biogenesis of Fe/S clusters in Saccharomyces cerevisiae. Proc. Natl. Acad. Sci. USA. 98: 1483-1488.

Volz, K. 1999. A test case for structure-based functional assignment: the $1.2 \mathrm{~A}$ crystal structure of the yjg F gene product from Escherichia coli. Protein Sci. 8: 2428-2437.

Wagner, A. 2001. How to reconstruct a large genetic network from $\mathrm{n}$ gene perturbations in fewer than $\mathrm{n}$ easy steps. Bioinformatics. 17: 1183-1197.

Wassarman, K.M., Repoila, F., Rosenow, C., Storz, G., and Gottesman, S. 2001. Identification of novel small RNAs using comparative genomics and microarrays. Genes Dev. 15: 1637-1651.

Weber, A., and Jung, K. 2002. Profiling Early OsmostressDependent Gene Expression in Escherichia coli Using DNA Macroarrays. J. Bacteriol. 184: 5502-5507.

Weinstock, G.M., Smajs, D., Hardham, J., and Norris, S.J. 2000. From microbial genome sequence to applications. Res. Microbiol. 151: 151-158.

Wen, Z.T., and Burne, R.A. 2002. Functional genomics approach to identifying genes required for biofilm development by Streptococcus mutans. Appl. Environ. Microbiol. 68: 1196-1203.

Xu, H., Aurora, R., Rose, G.D., and White, R.H. 1999. Identifying two ancient enzymes in Archaea using predicted secondary structure alignment. Nat. Struct. Biol. 6: 750-754.

Zarembinski, T.I., Hung, L.W., Mueller-Dieckmann, H.J., Kim, K.K., Yokota, H., Kim, R., and Kim, S.H. 1998. Structure-based assignment of the biochemical function of a hypothetical protein: a test case of structural genomics. Proc. Natl. Acad. Sci. USA. 95: 15189-15193. Zheng, L., Cash, V.L., Flint, D.H., and Dean, D.R. 1998. Assembly of iron-sulfur clusters. Identification of an iscSUA-hscBA-fdx gene cluster from Azotobacter vinelandii. J. Biol. Chem. 273: 13264-13272.

Zheng, L., White, R.H., Cash, V.L., Jack, R.F., and Dean, D.R. 1993. Cysteine desulfurase activity indicates a role for NIFS in metallocluster biosynthesis. Proc. Natl. Acad. Sci. USA. 90: 2754-2758.

Zheng, M., Wang, X., Templeton, L.J., Smulski, D.R., LaRossa, R.A., and Storz, G. 2001. DNA microarraymediated transcriptional profiling of the Escherichia coli response to hydrogen peroxide. J. Bacteriol. 183: 456270.

Zhou, J., and Miller, J.H. 2002. Microbial genomicschallenges and opportunities: the 9th International Conference on Microbial Genomes. J. Bacteriol. 184: 4327-4333. 


\section{Further Reading}

Caister Academic Press is a leading academic publisher of advanced texts in microbiology, molecular biology and medical research. Full details of all our publications at caister.com

- MALDI-TOF Mass Spectrometry in Microbiology Edited by: M Kostrzewa, S Schubert (2016) www.caister.com/malditof

- Aspergillus and Penicillium in the Post-genomic Era Edited by: RP Vries, IB Gelber, MR Andersen (2016) www.caister.com/aspergillus2

- The Bacteriocins: Current Knowledge and Future Prospects Edited by: RL Dorit, SM Roy, MA Riley (2016)

www.caister.com/bacteriocins

- Omics in Plant Disease Resistance Edited by: V Bhadauria (2016) www.caister.com/opd

- Acidophiles: Life in Extremely Acidic Environments Edited by: R Quatrini, DB Johnson (2016) www.caister.com/acidophiles

- Climate Change and Microbial Ecology: Current Research and Future Trend

Edited by: J Marxsen (2016)

www.caister.com/climate

- Biofilms in Bioremediation: Current Research and Emerging Technologies

Edited by: G Lear (2016)

www.caister.com/biorem

- Microalgae: Current Research and Applications Edited by: MN Tsaloglou (2016) www.caister.com/microalgae

- Gas Plasma Sterilization in Microbiology: Theory, Applications, Pitfalls and New Perspectives Edited by: H Shintani, A Sakudo (2016) www.caister.com/gasplasma

- Virus Evolution: Current Research and Future Directions Edited by: SC Weaver, M Denison, M Roossinck, et al. (2016) www.caister.com/virusevol

- Arboviruses: Molecular Biology, Evolution and Control Edited by: N Vasilakis, DJ Gubler (2016) www.caister.com/arbo

- Shigella: Molecular and Cellular Biology Edited by: WD Picking, WL Picking (2016) www.caister.com/shigella

-Aquatic Biofilms: Ecology, Water Quality and Wastewater Treatment

Edited by: AM Romaní, H Guasch, MD Balaguer (2016)

www.caister.com/aquaticbiofilms

- Alphaviruses: Current Biology

Edited by: S Mahalingam, L Herrero, B Herring (2016)

www.caister.com/alpha

- Thermophilic Microorganisms

Edited by: F Li (2015)

www.caister.com/thermophile
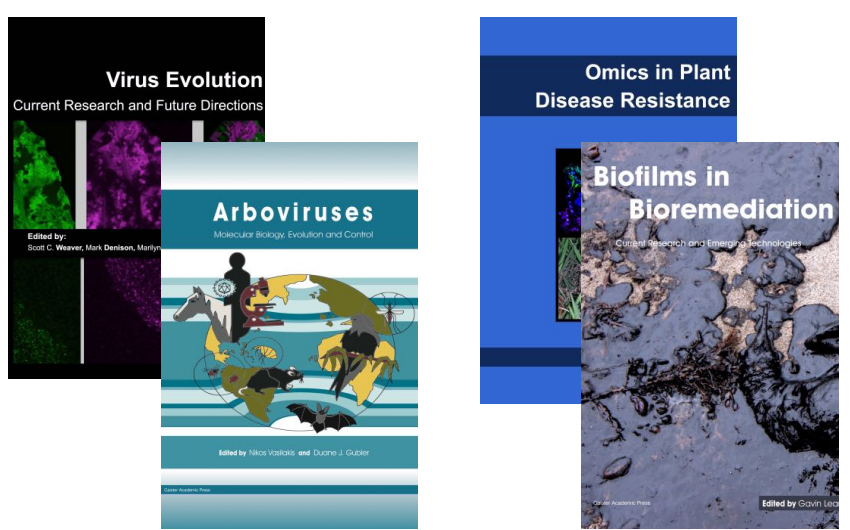
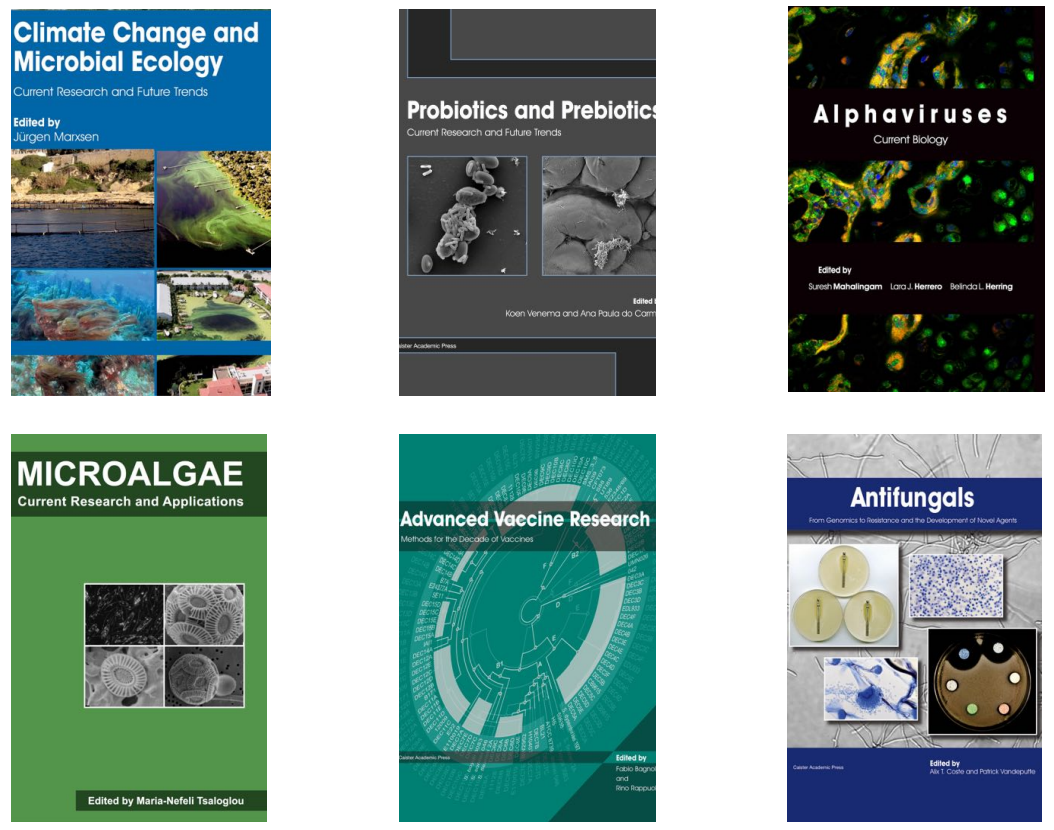

- Flow Cytometry in Microbiology: Technology and Applications Edited by: MG Wilkinson (2015) www.caister.com/flow

- Probiotics and Prebiotics: Current Research and Future Trends Edited by: K Venema, AP Carmo (2015) www.caister.com/probiotics

- Epigenetics: Current Research and Emerging Trends Edited by: BP Chadwick (2015) www.caister.com/epigenetics2015

- Corynebacterium glutamicum: From Systems Biology to Biotechnological Applications

Edited by: A Burkovski (2015)

www.caister.com/cory2

- Advanced Vaccine Research Methods for the Decade of Vaccines

Edited by: F Bagnoli, R Rappuoli (2015)

www.caister.com/vaccines

- Antifungals: From Genomics to Resistance and the Development of Novel Agents

Edited by: AT Coste, P Vandeputte (2015)

www.caister.com/antifungals

- Bacteria-Plant Interactions: Advanced Research and Future Trends Edited by: J Murillo, BA Vinatzer, RW Jackson, et al. (2015) www.caister.com/bacteria-plant

\section{- Aeromonas}

Edited by: J Graf (2015)

www.caister.com/aeromonas

- Antibiotics: Current Innovations and Future Trends

Edited by: S Sánchez, AL Demain (2015)

www.caister.com/antibiotics

- Leishmania: Current Biology and Contro Edited by: S Adak, R Datta (2015) www.caister.com/leish2

- Acanthamoeba: Biology and Pathogenesis (2nd edition) Author: NA Khan (2015)

www.caister.com/acanthamoeba2

- Microarrays: Current Technology, Innovations and Applications Edited by: Z He (2014)

www.caister.com/microarrays2

- Metagenomics of the Microbial Nitrogen Cycle: Theory, Methods and Applications

Edited by: D Marco (2014)

www.caister.com/n2 